\title{
Pain management after ambulatory surgery: a prospective, multicenter, randomized, double-blinded parallel controlled trial comparing nalbuphine and tramadol
}

Yu-jiao Guan' ${ }^{1}$ Lai Wei ${ }^{2}$, Qin Liao ${ }^{3}$, Qi-wu Fang ${ }^{4}$, Nong He ${ }^{5}$, Chong-fang Han ${ }^{6}$, Chang-hong Miao ${ }^{7}$, Gang-jian Luo ${ }^{8}$, Han-bing Wang ${ }^{9}$, Hao Cheng ${ }^{10}$, Qu-lian Guo ${ }^{1 *}$ and Zhi-gang Cheng ${ }^{1 *}$

\begin{abstract}
Background: Postoperative pain in ambulatory surgery is a multifactorial issue affecting patient satisfaction, time of discharge, and rehospitalization. This study evaluated the efficacy and safety of nalbuphine for the treatment of postoperative pain after ambulatory surgery, relative to tramadol.

Methods: This multi-center, randomized, double blind, and controlled study was conducted at 10 centers. In accordance with the inclusion criteria, 492 ambulatory surgery patients were recruited. These patients had moderate to severe pain after ambulatory surgery, with a visual analogue scale (VAS) score $>3 \mathrm{~cm}$. They were randomly divided into an experimental $(n=248)$ or control $(n=244)$ group and treated for analgesia with $0.2 \mathrm{mg} /$ $\mathrm{kg}$ of nalbuphine or $2 \mathrm{mg} / \mathrm{kg}$ of tramadol, respectively. VAS scores, adverse events, and vital signs of the patients were recorded before administration (baseline; $\left.T_{1}\right)$; and $30 \mathrm{~min}\left(T_{2}\right), 2 \mathrm{~h}\left(\mathrm{~T}_{3}\right), 4 \mathrm{~h}\left(\mathrm{~T}_{4}\right)$, and $6 \mathrm{~h}\left(\mathrm{~T}_{5}\right)$ after administration of analgesia. A decrease in pain intensity of more than $25 \%$ compared with the baseline was used as an indicator of analgesic efficacy. The experimental and control groups were compared with regard to this indicator of efficacy at each timepoint.
\end{abstract}

Results: The VAS scores of the experimental and control groups were statistically comparable at timepoints $T_{1}-T_{4}$. At $T_{5}$, the VAS scores of the experimental group were significantly lower than that of the control. The pain intensity was significantly higher in the experimental group compared with the control at $T_{2}$ and $T_{3}$. Adverse events and vital signs were similar for the two groups at each timepoint.

Conclusions: Nalbuphine can provide effective and safe pain relief in patients after ambulatory surgery.

Trial registration: The registration number is ChiCTR-IOR-16010032, the date of registration was 2016-11-28.

Keywords: Nalbuphine, Tramadol, Ambulatory surgery, Postoperative analgesia, Anesthesia, Pain

\footnotetext{
*Correspondence: qulianguo@hotmail.com; chengzg2004@hotmail.com 'Department of Anesthesiology, Xiangya Hospital of Central South University, No. 87 Xiangya Road, Changsha, Hunan, China

Full list of author information is available at the end of the article
}

C C The Author(s). 2020 Open Access This article is licensed under a Creative Commons Attribution 4.0 International License, which permits use, sharing, adaptation, distribution and reproduction in any medium or format, as long as you give appropriate credit to the original author(s) and the source, provide a link to the Creative Commons licence, and indicate if changes were made. The images or other third party material in this article are included in the article's Creative Commons licence, unless indicated otherwise in a credit line to the material. If material is not included in the article's Creative Commons licence and your intended use is not permitted by statutory regulation or exceeds the permitted use, you will need to obtain permission directly from the copyright holder. To view a copy of this licence, visit http://creativecommons.org/licenses/by/4.0/. The Creative Commons Public Domain Dedication waiver (http://creativecommons.org/publicdomain/zero/1.0/) applies to the data made available in this article, unless otherwise stated in a credit line to the data. 


\section{Background}

Postoperative pain is a multifactorial issue that may result in patient dissatisfaction, delayed discharge, and unanticipated hospital admission after ambulatory surgery [1]. Both delayed discharge and unanticipated hospital admission have the undesirable effect of increasing healthcare costs [2]. In the postoperative period, moderate to severe pain are frequently observed during the first 24 to $48 \mathrm{~h}$ after ambulatory surgery [3].

Patient recovery after ambulatory surgery has improved since the introduction of the concept of enhanced recovery after surgery, a multimodal perioperative care pathway designed to achieve early recovery after surgery [4]. Ambulatory surgery has significantly shortened hospitalization, accelerated turnover, and reduced hospital costs and rates of nosocomial infections [5]. However, the shortened hospitalization and increased mobility of surgical patients have necessitated the need to improve the efficacy of anesthesia and perioperative management. Therefore, postoperative pain and the complications arising from its treatment are important considerations for patients undergoing ambulatory surgery.

Various drugs have been used to prolong postoperative analgesia, such as tramadol [6], ketorolac [7], dexmedetomidine [8], ketamine [9], and nalbuphine [10]. Nalbuphine, a synthetic opioid agonist-antagonist analgesic, is primarily a kappa $(\kappa)$ agonist and a partial $\mathrm{mu}(\mu)$ antagonist. It has a better safety profile with fewer side effects compared with other opioids, because of its agonist and antagonist activities [11]. Nalbuphine [12] exerts its analgesic and hypnotic effects through its $\mathrm{\kappa}$ opioid receptor, which may reduce $\mu$ opioid receptor-related adverse events. Numerous studies $[13,14]$ have reported its advantages in pain management.

There have been few studies in China of nalbuphine for the treatment of postoperative pain after ambulatory surgery. The present study evaluated the analgesic efficacy and safety of intravenous nalbuphine hydrochloride, relative to tramadol, for the treatment of postoperative pain after ambulatory surgery, including a noninferiority control trial.

\section{Methods}

\section{Participants}

This study was approved by the Ethics Committee of Xiangya Hospital of Central South University (IRB 201608066). Written informed consent was obtained from all subjects participating in the trial. The trial was registered prior to patient enrollment at chictr.org.cn (ChiCTR-IOR-16010032, Principal investigator: Qulian Guo, Date of registration: 2016-11-26).

A multicenter, prospective, randomized, parallelcontrolled, double-blinded study for pain management after ambulatory surgery in adult patients was undertaken in 10 hospitals. Patients were screened at each center. The study was reported in accordance with the guidelines of the Consolidated Standards of Reporting Trials (CONSORT).

The patient inclusion criteria were as follows: 18 to 65 years old; ASA (American Society of Anesthesiologists) I-II; with postoperative pain after surgeries of the breast (except radical surgery for mastocarcinoma) or thyroid, or hysteroscopy, or laparoscopic cholecystectomy; operative time $<2 \mathrm{~h}$; visual analog scale (VAS) score $<3 \mathrm{~cm}$ before the surgery, and VAS score $>3 \mathrm{~cm}$ after recovery from anesthesia; body mass index (BMI) $18-29 \mathrm{~kg} / \mathrm{m}^{2}$, and signed informed consent.

Patients were excluded from this study if they were allergic to the medication or any of the excipients in the product. Patients with current or histories of any of the following were also excluded: opioid allergy; acute or chronic alcoholism or drug addiction; neurological disease; opioid used within the last 3 months; paralytic ileus; increased intracranial pressure or head injury; chronic opioid use (taking opioids for more than 3 months); hypotension; hypothyroidism, asthma (to be avoided during seizure); hypertrophy of the prostate; epilepsy; coronary heart disease; bronchial asthma; respiratory insufficiency; or respiratory failure. Patients taking or who had taken monoamine oxidase inhibitor or antidepressants within the past 15 days were excluded. Patients with abnormal preoperative liver and kidney function were also excluded, defined as abnormal alanine aminotransferase (ALT), aspartic aminotransferase (AST), blood urea nitrogen (BUN) or creatinine $(\mathrm{Cr})$ (ALT and AST $>1.5$ times the normal limit, and BUN and $\mathrm{Cr}$ higher than the normal limit); coronary heart disease; bronchial asthma; respiratory insufficiency or respiratory failure; or poorly controlled or difficult hypertension. The latter was defined as systolic blood pressure $(\mathrm{SBP}) \geq 160 \mathrm{mmHg}$ or diastolic pressure $(\mathrm{DBP}) \geq 100 \mathrm{mmHg}$. In addition, patients with any of the following were excluded: pregnancy; abnormal coagulation function; participation in another medication trial within the previous 30 days; unable to express their intention correctly; poor compliance; unable to complete the study program; or anyone the researchers considered inappropriate to participate.

\section{Trial design}

Patients were randomly assigned to receive either the experimental (group E) or control (group C) treatment in the postoperative period. Group E was treated with nalbuphine hydrochloride (1,161,101 Yichang Humanwell Pharmaceutical) diluted with saline to $1 \mathrm{mg} / \mathrm{L}$. Group C was administered tramadol hydrochloride diluted with saline to $10 \mathrm{mg} / \mathrm{L}$. 
The study medication was selected and prepared according to a random number list (nalbuphine hydrochloride or tramadol hydrochloride). The study was blinded, by excluding the researcher who prepared the postoperative medications from participating in test observations and follow-ups. The researchers involved in observation and evaluation of the experiment, and patients and doctors, were blinded throughout the study.

\section{Interventions}

All patients were administered intravenously with $5 \mathrm{mg}$ of dexamethasone before induction of general anesthesia, and $8 \mathrm{mg}$ of ondansetron at the time of surgery completion, to prevent postoperative nausea and vomiting. The bispectral index (BIS) value was maintained between 40 and 60 during the operation. Anesthesia induction was performed using sufentanil $(0.5 \mu \mathrm{g} / \mathrm{kg})$ and propofol $(2-2.5 \mathrm{mg} / \mathrm{kg})$, with cisatracurium $(0.1-0.2 \mathrm{mg} / \mathrm{kg})$ given when necessary. Anesthesia was maintained by simultaneous infusion of propofol and remifentanil $(0.1-0.15 \mu \mathrm{g} / \mathrm{kg} / \mathrm{min})$. An additional $0.1 \mathrm{mg} / \mathrm{kg}$ of cisatracurium was added intraoperatively when required. Intraoperative fluid infusion and other anesthetic management were performed routinely.

After the surgery, patients who were fully awake and feeling pain for the first time were assessed for pain while at rest, using the VAS. If the VAS score was $>3$ $\mathrm{cm}$, the patients were included in the study and the pain score was used as the baseline $\left(T_{1}\right)$. The test medications (nalbuphine hydrochloride or tramadol hydrochloride) were administered at $0.2 \mathrm{~mL} / \mathrm{kg}$. The VAS at rest was used to evaluate the efficacy of the medications and was recorded before administration $\left(\mathrm{T}_{1}\right)$, and after administration at $30 \mathrm{~min}\left(\mathrm{~T}_{2}\right), 2 \mathrm{~h}\left(\mathrm{~T}_{3}\right), 4 \mathrm{~h}\left(\mathrm{~T}_{4}\right)$, and $6 \mathrm{~h}\left(\mathrm{~T}_{5}\right)$. The following vital signs were recorded at each timepoint: SBP, DBP, mean arterial pressure (MAP), heart rate, and respiratory rate. Adverse events and any medications used were also recorded.

Within $2 \mathrm{~h}$ after administration of the medications, if the VAS score was $>3 \mathrm{~cm}$, it was deemed that the analgesic effect was invalid, and the patient was discontinued from the trial. One hundred milligrams of flurbiprofen axetil was infused intravenously as a rescue analgesia, and the name and dose were recorded. The use of other analgesics aside from those involved in the study, such as opioids, tranquilizers, anesthetics and antiemetics, were prohibited during the study period. If other analgesics were required to control the pain, the patient was discontinued.

\section{Outcomes}

\section{Primary outcome}

The pain intensity was measured using the VAS. A decrease in VAS score of more than $25 \%$ compared with the baseline was used as an indicator of analgesic efficacy [15]. The VAS score was also compared between groups $\mathrm{E}$ and $\mathrm{C}$ at all timepoints to determine any differences in the efficacy and duration of the analgesic effects.

\section{Secondary outcome}

The vital signs (SBP, DBP, respiratory rate and heart rate) were measured and used as safety indicators. The vital signs were also compared between groups $\mathrm{E}$ and $\mathrm{C}$, and within each group, at each timepoint. Any differences observed could be used as a secondary indicator to determine analgesic efficacy.

\section{Adverse events}

Adverse events such as medication extravasation, dizziness, nausea, vomiting, and hidrosis were recorded during the study. The rates of adverse events was compared between groups $\mathrm{E}$ and $\mathrm{C}$ to determine the effects of the treatments.

\section{Sample size}

Sample size was calculated by VAS at rest at each timepoint. Based on a previous report [16], a single intravenous injection of tramadol was administered to patients with postoperative pain after day surgery, and the VAS score was $\sim 2.43 \mathrm{~cm}$ at $30 \mathrm{~min}$ after administration. Assuming that the analgesic effect of nalbuphine was better than tramadol, with $\alpha=0.05$ and $\beta=0.2$, the VAS score difference between the two groups $\left(\mu_{\mathrm{A}}-\mu_{\mathrm{B}}\right)$ would be 0.5 and the standard deviation $\sigma=1.7$. The sample $\operatorname{size}(\mathrm{n})$ was calculated using the formula [17]:

$$
n=2\left[\alpha\left(z_{1-} \alpha / 2+z_{1-\beta}\right) /\left(\mu_{\mathrm{A}}-\mu_{\mathrm{B}}\right)\right]^{2}
$$

Each group required 182 subjects and with consideration of the estimated dropout rate, 250 patients were included in each group. Therefore, 500 patients were recruited in this study, with 50 patients in each center.

\section{Statistical methods}

Descriptive statistics were used to describe all demographic data. The $t$-test was applied to analyze the changes in VAS scores between the two treatment groups at each timepoint, and at different timepoints relative to the baseline. The Wilcoxon test was used to analyze the pain classification of patients at each observation timepoint. The pain intensity between the two groups was compared using the chi-squared $\left(\chi^{2}\right)$ test. $P<0.05$ was considered statistically significant. The incidence of adverse events, changes in blood pressure, respiratory rate, and heart rate relative to the baseline at 
each timepoint, and differences between the groups, were analyzed using the $t$-test.

\section{Results}

\section{Participants}

The study population comprised 492 randomly coded patients recruited from 10 centers (Fig. 1). However, 55 patients were excluded as they did not meet the eligibility criteria of a VAS score $<4 \mathrm{~cm}$. Thus, the trial consisted of 437 patients: 209 in group E, and 228 in group $\mathrm{C}$.

\section{Baseline data}

The differences in age and gender between groups $\mathrm{E}$ and $C$ were not statistically significant (Table 1). The results of the preoperative test, physical examination, and medical histories of the two groups were relatively similar, with no statistical difference. There were no statistically significant differences in the types of surgery between the two groups (Table 2). There were also no differences in the use of opioids including sufentanil and remifentanil between the two groups, during surgery.

During the observation period, 14 (6.3\%) and 20 (9.0\%) patients in groups $\mathrm{E}$ and $\mathrm{C}$, respectively, were treated with rescue analgesic medication consisting of $100 \mathrm{mg}$ of flurbiprofen axetil. There was no statistically significant difference between the two groups
Table 1 Patient demographics of groups $E$ and $C^{a}$

\begin{tabular}{|c|c|c|c|}
\hline & Group E & Group C & $P$ \\
\hline Subjects, n & 209 & 228 & \\
\hline \multicolumn{4}{|l|}{ Gender, n (\%) } \\
\hline Male & $52(25.0)$ & $48(21.1)$ & 0.340 \\
\hline Female & $156(75.0)$ & 179 (78.9) & \\
\hline Age, y & $40.66 \pm 12.04$ & $40.67 \pm 11.81$ & 0.994 \\
\hline $\mathrm{BMI}, \mathrm{kg} / \mathrm{m}^{2}$ & $23.15 \pm 2.84$ & $23.20 \pm 2.87$ & 0.847 \\
\hline Respiration, rpm & $17.09 \pm 1.81$ & $17.04 \pm 2.18$ & 0.808 \\
\hline Heart rate, bpm & $74.45 \pm 8.43$ & $74.48 \pm 9.75$ & 0.978 \\
\hline \multicolumn{4}{|c|}{ Heart rhythm, n (\%) } \\
\hline Normal & $207(99.0)$ & $225(99.1)$ & 1.000 \\
\hline Abnormal & $2(1.0)$ & $2(0.9)$ & \\
\hline $\mathrm{SBP}, \mathrm{mmHg}$ & $121.63 \pm 16.26$ & $122.64 \pm 16.01$ & 0.513 \\
\hline $\mathrm{DBP}, \mathrm{mmHg}$ & $74.92 \pm 9.48$ & $74.63 \pm 8.80$ & 0.738 \\
\hline MAP, mmHg & $92.91 \pm 11.65$ & $93.17 \pm 10.84$ & 0.806 \\
\hline
\end{tabular}

aroup E was treated with nalbuphine hydrochloride diluted with saline to 1 $\mathrm{mg} / \mathrm{L}$. Group C was administered tramadol hydrochloride diluted with saline to $10 \mathrm{mg} / \mathrm{L}$.

with regard to the percentage using rescue analgesic medication $\left(X^{2}=1.206 ; P=0.272\right)$. There was no significant deviation from the regimen for all concomitant and combination medications and no statistically significant difference between the two groups.

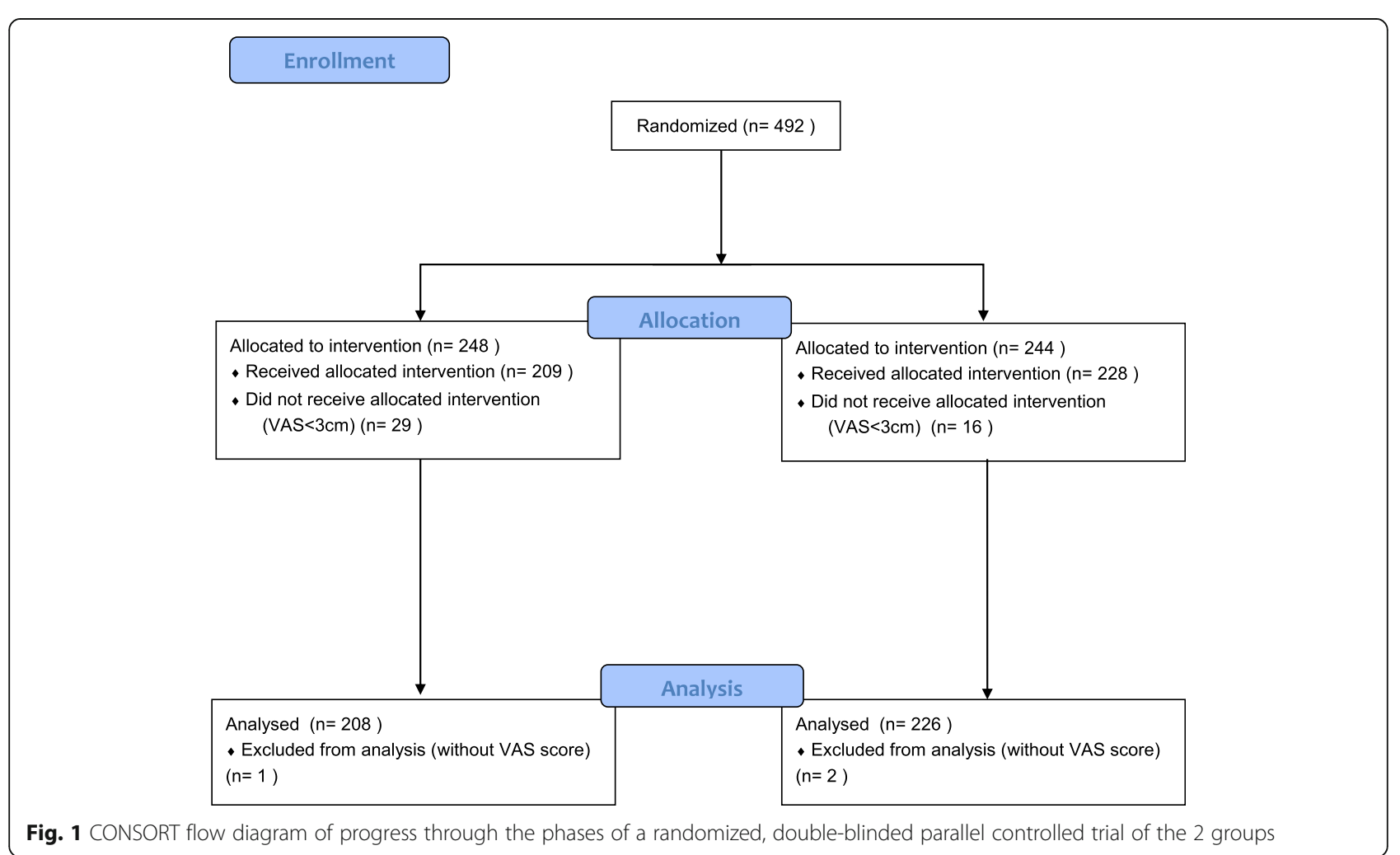


Table 2 Types of surgery, $\mathrm{n}(\%)^{\mathrm{a}}$

\begin{tabular}{lllllll}
\hline & Total, $n$ & Breast & Thyroid & Hysteroscopy & LC & Others \\
\hline Group E & 209 & $27(12.9)$ & $41(19.6)$ & $39(18.7)$ & $91(43.5)$ & $11(5.3)$ \\
Group C & 228 & $26(11.4)$ & $45(19.7)$ & $44(19.3)$ & $106(46.5)$ & $7(3.1)$
\end{tabular}

${ }^{a}$ Reported as $\mathrm{n}(\%)$, unless indicated otherwise. Group E was treated with nalbuphine hydrochloride diluted with saline to $1 \mathrm{mg} / \mathrm{L}$. Group $\mathrm{C}$ was administered tramadol hydrochloride diluted with saline to $10 \mathrm{mg} / \mathrm{L}$. Other surgeries included: lumbar disc exploration, laparoscopic gastric perforation repair, endoscopic sinus surgery, surgical removal of internal fixation of fractured bones.LC, laparoscopic cholecystectomy

\section{Outcomes}

\section{Primary outcome}

A pairwise comparison of the VASs determined at rest at different timepoints between groups $\mathrm{E}$ and $\mathrm{C}$ revealed no difference between the VAS scores at $\mathrm{T}_{1}, \mathrm{~T}_{2}, \mathrm{~T}_{3}$, or $\mathrm{T}_{4}$, respectively. However, at $T_{5}$ the VAS at rest of group $E$ was significantly lower than that of group $C$ (Fig. 2). A decrease in pain intensity of more than $25 \%$ compared with the baseline $\left(\mathrm{T}_{1}\right)$ was used as an indicator of analgesic efficacy (Table 3). The analgesic efficacy experienced by group $\mathrm{E}$ at $\mathrm{T}_{2}$ and $\mathrm{T}_{3}$ was significantly higher than that of group $C$.

\section{Adverse events}

Adverse events occurred in 6 (2.9\%) subjects in group E and $3(1.3 \%)$ subjects in group C, with no serious adverse events or deaths occurring in either group. The number of adverse events was higher in group E compared with group $\mathrm{C}$, but the difference was not statistically significant (Table 4).

\section{Secondary outcome}

The vital signs (SBP, DBP, respiratory rate, and heart rate) of groups $\mathrm{E}$ and $\mathrm{C}$ at all timepoints were statistically

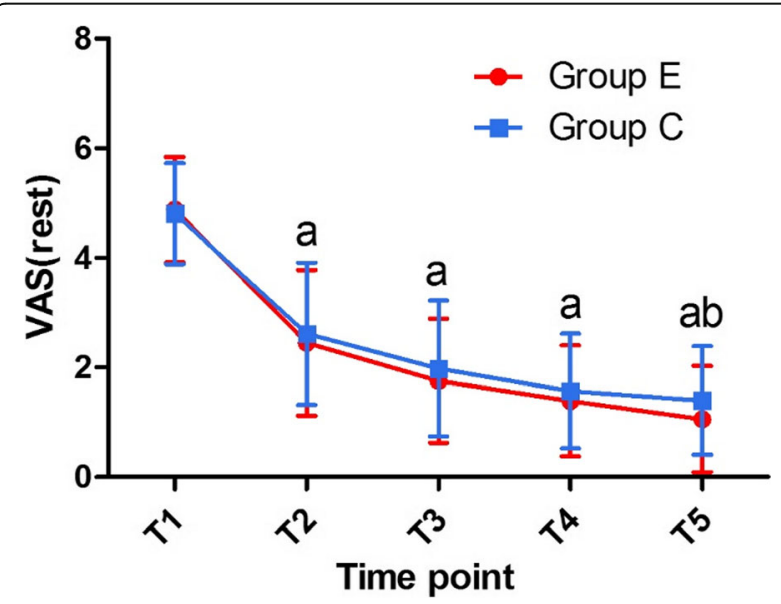

Fig. 2 The VAS at rest in the experimental (Group E) and control group (Group C). Time points: $T_{1}$ : before administration; $T_{2}$ : after administration at $30 \mathrm{~min} ; \mathrm{T}_{3}$ : after administration at $2 \mathrm{~h}$; $\mathrm{T}_{4}$ : after administration at $4 \mathrm{~h} ; \mathrm{T}_{5}$ : after administration at $6 \mathrm{~h}$. ${ }^{\mathrm{a}} \mathrm{After}$ administration, the VAS of Group E was lower than that of Group C, from $T_{2}-T_{5}$; ${ }^{b}$ there was a statistically significant difference in VAS between the 2 groups at $T_{5}$. Data are expressed as

mean \pm standard deviation similar (Table 5). For both groups, the mean SBP, DBP, and heart rate at each of the timepoints $\mathrm{T}_{2}, \mathrm{~T}_{3}, \mathrm{~T}_{4}$, and $\mathrm{T}_{5}$ were significantly lower than at $\mathrm{T}_{1}$. However, the blood pressures at $T_{2}$ to $T_{5}$ were comparable to that at admission $\left(\mathrm{T}_{0}\right)$, and there was no significant difference in respiratory rates.

\section{Discussion}

In this prospective, multicenter study, 437 patients were randomized to receive either nalbuphine (group E) or tramadol (group C) to treat pain after ambulatory surgery. Group E experienced significantly longer duration of analgesia compared with group C. At each timepoint, the vital signs (SBP, DBP, respiratory rate, and heart rate) of the 2 groups were statistically comparable. However, within each group there were significant differences in SBP, DBP, and heart rate at $T_{2}, T_{3}, T_{4}$, and $T_{5}$, relative to $T_{1}$. Overall, the analgesic effect of nalbuphine was comparable to that of tramadol, with nalbuphine having a longer duration of analgesia.

In China, the number of day surgeries is increasing due to improvements in surgery and anesthesia, with shorter recovery time and patients discharged within 24 $\mathrm{h}$ after surgery. Therefore, there is a higher demand for

Table 3 Pain reduction when compared to baseline $\left(T_{1}\right), n(\%)^{a}$

\begin{tabular}{llllll}
\hline & & Group E & Group $C^{c}$ & $X^{2}$ & $P$ \\
\hline $\mathrm{T}_{2}{ }^{\mathrm{d}}$ & Effective & $186(89.0)$ & $178(78.4)$ & 8.837 & 0.003 \\
& Noneffective & $23(11.0)$ & $49(21.6)$ & & \\
$\mathrm{T}_{3}{ }^{\mathrm{e}}$ & Effective & $192(97.0)$ & $195(90.7)$ & 6.874 & 0.009 \\
& Noneffective & $6(3.0 \%)$ & $20(9.3 \%)$ & & \\
$\mathrm{T}_{4}{ }^{\mathrm{f}}$ & Effective & $190(97.4)$ & $203(97.1)$ & 0.036 & 0.850 \\
& Noneffective & $5(2.6)$ & $6(2.9)$ & & \\
$\mathrm{T}_{5}{ }^{\mathrm{g}}$ & Effective & $189(97.9)$ & $201(97.6)$ & 0.000 & 1.000 \\
& Noneffective & $4(2.1)$ & $5(2.4)$ & & \\
\hline
\end{tabular}

${ }^{a}$ Effective pain reduction is defined as a decrease in pain intensity $>25 \%$, compared with the baseline $\left(\mathrm{T}_{1}\right)$. Noneffective is defined as a decrease in pain intensity $<25 \%$, compared with the baseline $\left(T_{1}\right)$

${ }^{b}$ Group $E(n=209)$ was treated with nalbuphine hydrochloride diluted with saline to $1 \mathrm{mg} / \mathrm{L}$.

'Group C $(n=228)$ was administered tramadol hydrochloride diluted with saline to $10 \mathrm{mg} / \mathrm{L}$.

${ }^{\mathrm{d}} \mathrm{T}_{2}$ : after administration at $30 \mathrm{~min}$

${ }^{\mathrm{e}} \mathrm{T}_{3}$ : after administration at $2 \mathrm{~h}$

${ }^{\mathrm{f}} \mathrm{T}_{4}$ : after administration at $4 \mathrm{~h}$

${ }^{9} \mathrm{~T}_{5}$ : after administration at $6 \mathrm{~h}$ 
Table 4 Patients experiencing adverse events, $n$

\begin{tabular}{lll}
\hline & Group E & Group C \\
\hline Total subjects experiencing adverse events & 6 & 3 \\
Vasculitis, medication extravasation & 1 & 0 \\
Dizziness, nausea, vomiting & 5 & 2 \\
Hidrosis & 0 & 1 \\
\hline
\end{tabular}

anesthesia and a need to improve the quality of analgesics. While achieving rapid recovery, patients also need to avoid complications related to surgery and anesthesia, such as pain, nausea, and vomiting. Numerous studies $[17,18]$ have shown that after day surgery nearly $80 \%$ of patients experience pain. Postoperative pain not only affects patients' rehabilitation and prolongs hospitalization, it can also result in progression from acute to chronic

Table 5 Vital signs at each timepoint ${ }^{a}$

\begin{tabular}{|c|c|c|c|c|}
\hline & Vital signs & Group $E^{b}$ & Group $C^{c}$ & $P$ \\
\hline \multirow[t]{4}{*}{$\mathrm{T}_{0}$} & SBP & $121.63 \pm 16.26$ & $122.64 \pm 16.01$ & 0.513 \\
\hline & $\mathrm{DBP}$ & $74.92 \pm 9.48$ & $74.63 \pm 8.80$ & 0.738 \\
\hline & Respiratory rate & $17.09 \pm 1.81$ & $17.04 \pm 2.18$ & 0.808 \\
\hline & Heart rate & $74.45 \pm 8.43$ & $74.48 \pm 9.75$ & 0.978 \\
\hline \multirow[t]{4}{*}{$\mathrm{T}_{1}$} & SBP & $128.96 \pm 17.74^{* *}$ & $130.18 \pm 17.05^{* *}$ & 0.465 \\
\hline & $\mathrm{DBP}$ & $79.04 \pm 11.32^{* *}$ & $78.85 \pm 11.45^{* *}$ & 0.864 \\
\hline & Respiratory rate & $16.52 \pm 2.40$ & $16.89 \pm 2.56$ & 0.121 \\
\hline & Heart rate & $78.69 \pm 16.33$ & $78.89 \pm 14.97$ & 0.893 \\
\hline \multirow[t]{4}{*}{$\mathrm{T}_{2}$} & SBP & $123.87 \pm 16.07^{*}$ & $126.10 \pm 16.68^{*}$ & 0.157 \\
\hline & $\mathrm{DBP}$ & $76.20 \pm 9.88^{*}$ & $77.12 \pm 12.16^{*}$ & 0.390 \\
\hline & Respiratory rate & $16.74 \pm 2.19$ & $17.12 \pm 2.46$ & 0.092 \\
\hline & Heart rate & $76.82 \pm 13.95^{*}$ & $76.54 \pm 12.06^{*}$ & 0.822 \\
\hline \multirow[t]{4}{*}{$\mathrm{T}_{3}$} & SBP & $118.37 \pm 15.23^{*}$ & $121.18 \pm 15.53^{*}$ & 0.065 \\
\hline & DBP & $72.82 \pm 9.19^{*}$ & $74.00 \pm 9.70^{*}$ & 0.209 \\
\hline & Respiratory rate & $16.53 \pm 1.85$ & $16.72 \pm 2.13$ & 0.321 \\
\hline & Heart rate & $74.06 \pm 10.82^{*}$ & $74.59 \pm 9.58^{*}$ & 0.598 \\
\hline \multirow[t]{4}{*}{$\mathrm{T}_{4}$} & SBP & $116.72 \pm 15.43^{*}$ & $118.82 \pm 15.19^{*}$ & 0.169 \\
\hline & $\mathrm{DBP}$ & $71.27 \pm 9.36^{*}$ & $72.07 \pm 9.73^{*}$ & 0.399 \\
\hline & Respiratory rate & $16.44 \pm 1.78$ & $16.62 \pm 2.20$ & 0.366 \\
\hline & Heart rate & $72.81 \pm 9.44^{*}$ & $73.62 \pm 8.99^{*}$ & 0.378 \\
\hline \multirow[t]{4}{*}{$\mathrm{T}_{5}$} & SBP & $116.53 \pm 14.86^{*}$ & $117.11 \pm 14.46^{*}$ & 0.691 \\
\hline & DBP & $70.64 \pm 9.39^{*}$ & $70.63 \pm 9.45^{*}$ & 0.986 \\
\hline & Respiratory rate & $16.46 \pm 1.84$ & $16.54 \pm 2.07$ & 0.682 \\
\hline & Heart rate & $72.65 \pm 9.35^{*}$ & $72.76 \pm 9.22^{*}$ & 0.905 \\
\hline
\end{tabular}

${ }^{\mathrm{a}} \mathrm{T}_{0}$ : at admission, $\mathrm{T}_{1}$ : before administration, $\mathrm{T}_{2}$ : after administration at $30 \mathrm{~min}$, $T_{3}$ : after administration at $2 \mathrm{~h}, \mathrm{~T}_{4}$ : after administration at $4 \mathrm{~h}, \mathrm{~T}_{5}$ : after administration at $6 \mathrm{~h}$

${ }^{\mathrm{b}} \mathrm{Group} \mathrm{E}(n=209)$ was treated with nalbuphine hydrochloride diluted with saline to $1 \mathrm{mg} / \mathrm{L}$.

'Group C ( $n=228)$ was administered tramadol hydrochloride diluted with saline to $10 \mathrm{mg} / \mathrm{L}$.

*Difference is statistically significant compared with $\mathrm{T}_{1}$; ${ }^{* *}$ difference is statistically significant compared with $\mathrm{T}_{0}$ pain, which is the main cause of readmission after day surgery [19].

According to the Chinese Society of Anesthesiology [20], systemic opioids given to patients undergoing ambulatory surgery with general anesthesia activate opioid receptors and stimulate various organs. This often results in nausea and vomiting, pruritus, urinary retention, excessive sedation and respiratory inhibition. Thus, in principle, systemic opioids are not used for postoperative pain relief after day surgery. The analgesic and adverse reactions of mixed agonist-antagonist opioids, such as nalbuphine and dezocine, also exhibit a ceiling effect. Implementation of multimodal analgesia using NSAIDs can significantly reduce the dose of opioid and adverse reactions, and can be used postoperatively to manage moderate pain after ambulatory surgery.

Nalbuphine, a mixed agonist-antagonist opioid, is associated with milder $\mu$ receptor-related side effects. Its plasma half-life is $5 \mathrm{~h}$, and in clinical studies the duration of analgesic activity ranges from 3 to $6 \mathrm{~h}$ [21]. In our study, the VAS at rest of group E was less than 4 points, and the difference was statistically significant compared with the VAS at rest before administration. This indicates that nalbuphine could effectively relieve pain after ambulatory surgery. Similar results were also observed in animal studies that showed amelioration of somatic and visceral pain in mice after treatment with nalbuphine [22].

In the present study, the VAS at rest at timepoints $\mathrm{T}_{1}$ to $\mathrm{T}_{4}$ of the nalbuphine group (group E) did not differ from that of the control. At $\mathrm{T}_{5}$, the VAS at rest of the nalbuphine group was significantly lower than that of the tramadol group. This indicates that the duration of nalbuphine for pain relief after ambulatory surgery was longer than that of tramadol. There were 6 cases $(2.8 \%)$ of adverse reactions in the nalbuphine group, which was not significantly different from the 3 cases $(1.3 \%)$ in the tramadol group.

The incidence of adverse reactions associated with nalbuphine is relatively low compared with other opioid medications. A meta-analysis of randomized controlled trials by Zeng et al. [23] showed that nalbuphine has similar analgesic effects compared to morphine, and a better drug safety profile with a low incidence of postoperative pruritus, respiratory inhibition, nausea, and vomiting. In addition, studies have reported that antagonism of the $\mu$ receptor by nalbuphine could reduce the adverse reactions of other opioids, as seen in the combination of morphine and nalbuphine in patientcontrolled analgesia or patient-controlled epidural analgesia [24, 25]; and the rate of adverse effects such as urinary retention related to morphine, pruritus, and nausea was significantly less. Nalbuphine with sufentanil used in patient-controlled analgesia could reduce the 
incidence of opioid-related nausea and vomiting and improved patients' satisfaction with analgesia [26, 27].

In the present study, the difference in respiratory rates before and after administration in both the nalbuphine and tramadol groups was not statistically significant, and no respiratory depression was observed. Many studies have reported that respiratory depression caused by nalbuphine is small and has a ceiling effect $[28,29]$. In one study, a neonate was wrongly administered a ten-fold higher dose than required of nalbuphine, and it resulted in only prolonged sedation with no respiratory failure [30].

Studies have shown that pre-anesthetic injections of nalbuphine could reduce stress responses and fluctuations in blood pressure and heart rate during intubation [31, 32]. In the present study, the blood pressures and heart rates of both groups after administration were significantly lower than at $\mathrm{T}_{1}$, although still within normal ranges. The blood pressure at $\mathrm{T}_{0}$ (Inception of the study) was compared to the blood pressure after surgery $\left(T_{1}-T_{5}\right)$; the blood pressure at $\mathrm{T}_{1}$ was significantly higher than at $\mathrm{T}_{0}$. However, at the later timepoints, $T_{2}$ to $T_{5}$, there were no statistical differences in the blood pressures compared to $\mathrm{T}_{0}$. The decrease in blood pressure after administration $\left(\mathrm{T}_{2}-\mathrm{T}_{5}\right)$ may have been due to the alleviation of pain. If so, then the lowered blood pressure could also indicate the analgesic efficacy of nalbuphine.

There are several limitations in this study. First, a limited number of parameters (VAS score, adverse events, and change of vital signs) were observed within the halflife of the medication. Secondly, the VAS scores were recorded at rest and not during movement. Finally, due to ethical issues a placebo control group was not possible. Therefore, we were not able to assess the effectiveness of nalbuphine or tramadol at 4 and $6 \mathrm{~h}$ after administration. Fortunately, none of the patients dropped out during the 4 or $6 \mathrm{~h}$ after administration of medication for pain. However, the present results warrant further experiments to determine comprehensively the effectiveness and safety of nalbuphine for the treatment of pain after ambulatory surgery.

\section{Conclusion}

This study indicates that nalbuphine at a recommended dose of $0.2 \mathrm{mg} / \mathrm{kg}$ is safe and effective for pain management after ambulatory surgery.

\section{Abbreviations}

ALT: alanine aminotransferase; ASA: American Society of Anesthesiologists; AST: Aspartic aminotransferase; BIS: Bispectral index; BMI: Body mass index; BUN: Blood urea nitrogen; C: Control; CONSORT: Consolidated Standards of Reporting Trials; Cr: Creatinine; DBP: Diastolic pressure; E: Experimental; MAP: Mean arterial pressure; SBP: Systolic blood pressure; VAS: Visual analog scale

\section{Acknowledgements}

Not applicable.

\section{Authors' contributions}

GYJ: This author contributed to the data collection, contributed to the data analysis and wrote the manuscript. WL: This author contributed to the data collection and analysis. LQ: This author contributed to the data collection and analysis. FQW: This author contributed to the data collection and analysis. HN This author contributed to the data collection and analysis. HCF: This author contributed to the data collection and analysis. MCH: This author contributed to the data collection and analysis. LCJ: This author contributed to the data collection and analysis. WHB: This author contributed to the data collection and analysis. $\mathrm{CH}$ : This author contributed to the data collection and analysis. GQL: This author designed most of the research plan, contributed to the data collection. CZG: This author designed most of the research plan, contributed to the data collection. All of the authors have read and approved the manuscript.

\section{Funding}

Not applicable.

\section{Availability of data and materials}

The datasets generated and analyzed during the present study are available from the corresponding author on reasonable request.

\section{Ethics approval and consent to participate}

This study was approved by the Ethics Committee of Xiangya Hospital of Central South University (IRB 201608066). Written informed consent was obtained from all subjects participating in the trial. The trial was registered prior to patient enrollment at chictr.org.cn (ChiCTR-IOR-16010032, Principal investigator: Qulian Guo, Date of registration: 2016-11-26).

\section{Consent for publication}

All data published here are under the consent for publication. Written informed consent was obtained from all individual participants included in the study.

\section{Competing interests}

The authors declare that they have no conflict of interest.

\section{Author details}

${ }^{1}$ Department of Anesthesiology, Xiangya Hospital of Central South University, No. 87 Xiangya Road, Changsha, Hunan, China. ${ }^{2}$ Department of Anesthesiology, Hunan Provincial People's Hospital, Changsha, Hunan, China. ${ }^{3}$ Department of Anesthesiology, Third Xiangya Hospital of Central South University, Changsha, Hunan, China. ${ }^{4}$ Department of Anesthesiology, Pain Medicine \& Critical Care Medicine, Aviation General Hospital of China Medical University \& Beijing Institute of Translational Medicine, Chinese Academy of Sciences, Beijing, China. ${ }^{5}$ Department of Anesthesiology, Peking University Shougang Hospital, Beijing, China. ${ }^{6}$ Department of Anesthesiology, Shanxi Academy of Medical Sciences, Shanxi Dayi Hospital, Shanxi, China. ${ }^{7}$ Department of Anesthesiology, Fudan University Shanghai Cancer Center, Shanghai, China. ${ }^{8}$ Department of Anesthesiology, Third Affiliated Hospital of Sun Yat-Sen University, Guangzhou, Guangdong, China. ${ }^{9}$ Department of Anesthesiology, First People's Hospital of Foshan, Foshan, Guangdong, China.

${ }^{10}$ Department of Anesthesiology, Beijing Ditan Hospital Capital Medical University, Beijing, China.

Received: 31 March 2020 Accepted: 11 August 2020 Published online: 15 August 2020

\section{References}

1. Shirakami G, Teratani Y, Namba T, Hirakata H, Tazuke-Nishimura M, Fukuda K. Delayed discharge and acceptability of ambulatory surgery in adult outpatients receiving general anesthesia. J Anesth. 2005;19:93-101. https:// doi.org/10.1007/s00540-004-0297-6.

2. Tong D, Chung F. Postoperative pain control in ambulatory surgery. Surg Clin North Am. 1999;79:401-30.

3. Rawal N. Postoperative pain treatment for ambulatory surgery. Best Pract Res Clin Anaesthesiol. 2007;21:129-48. 
4. Melnyk M, Casey RG, Black P, Koupparis AJ. Enhanced recovery after surgery (ERAS) protocols: Time to change practice? Can Urol Assoc J. 2011;5:342-8. https://doi.org/10.5489/cuaj.11002.

5. Lee JH. Anesthesia for ambulatory surgery. Korean J Anesthesiol. 2017;70: 398-406. https://doi.org/10.4097/kjae.2017.70.4.398.

6. Acalovschi I, Cristea T, Margarit S, Gavrus R. Tramadol added to lidocaine for intravenous regional anesthesia. Anesth Analg. 2001;92:209-14.

7. Jankovic RJ, Visnjic MM, Milic DJ, Stojanovic MP, Djordjevic DR, Pavlovic MS. Does the addition of ketorolac and dexamethasone to lidocaine intravenous regional anesthesia improve postoperative analgesia and tourniquet tolerance for ambulatory hand surgery? Minerva Anestesiol. 2008;74:521-7.

8. Kumar A, Sharma D, Datta B. Addition of ketamine or dexmedetomidine to lignocaine in intravenous regional anesthesia: A randomized controlled study. J Anaesthesiol Clin Pharmacol. 2012;28:501-4. https://doi.org/10.4103/ 0970-9185.101941.

9. Abdel-Ghaffar HS, Kalefa MA, Imbaby AS. Efficacy of ketamine as an adjunct to lidocaine in intravenous regional anesthesia. Reg Anesth Pain Med. 2014; 39:418-22. https://doi.org/10.1097/AAP.0000000000000128.

10. Youssef MIEN. Lidocaine-nalbuphine versus lidocaine-tramadol for intravenous regional anesthesia. Ain-Shams J Anesthesiol. 2014;7:198-204.

11. Bakri MH, Ismail EA, Abd-Elshafy SK. Analgesic effect of Nalbuphine when added to intravenous regional anesthesia: a randomized control trial. Pain Physician. 2016;19:575-81.

12. Vilsbøll T. The effects of glucagon-like peptide-1 on the beta cell. Diabetes Obes Metab. 2009;11 Suppl 3:11-8. https://doi.org/10.1111/j.1463-1326.2009. 01073.x.

13. Shin D, Kim S, Kim CS, Kim HS. Postoperative pain management using intravenous patient-controlled analgesia for pediatric patients. J Craniofac Surg. 2001;12:129-33.

14. Mukherjee A, Pal A, Agrawal J, Mehrotra A, Dawar N. Intrathecal nalbuphine as an adjuvant to subarachnoid block: What is the most effective dose? Anesth Essays Res. 2011;5:171-5. https://doi.org/10.4103/0259-1162.94759.

15. Hua X, Chen LM, Zhu Q, Hu W, Lin C, Long ZQ, et al. Efficacy of controlledrelease oxycodone for reducing pain due to oral mucositis in nasopharyngeal carcinoma patients treated with concurrent chemoradiotherapy: a prospective clinical trial. Support Care Cancer. 2019; 27:3759-67. https://doi.org/10.1007/s00520-019-4643-5.

16. Ali M, Khan FA. Comparison of analgesic effect of tramadol alone and a combination of tramadol and paracetamol in day-care laparoscopic surgery. Eur J Anaesthesiol. 2009;26:475-9. https://doi.org/10.1097/EJA. Ob013e328324b747.

17. Chow S-C, Shao J, Wang H. Sample size calculations in clinical research (2nd ed). Boca Raton: Chapman \& Hall/CRC; 2008

18. Apfelbaum JL, Chen C, Mehta SS, Gan TJ. Postoperative pain experience: results from a national survey suggest postoperative pain continues to be undermanaged. Anesth Analg. 2003;97:534-40 table of contents.

19. Aubrun F, Ecoffey C, Benhamou D, Jouffroy L, Diemunsch P, Skaare K, et al. Perioperative pain and post-operative nausea and vomiting (PONV) management after day-case surgery: The SFAR-OPERA national study. Anaesth Crit Care Pain Med. 2018. https://doi.org/10.1016/j.accpm.2018.08.004.

20. Xu J. Expert consensus on analgesia afteradult day surgery. J Clin Anesthesiol. 2017;08:812-5.

21. Web site:LABEL: NALBUPHINE HYDROCHLORIDE- nalbuphine hydrochloride injection, solution. Available at: https://www.dailymed.n/m.nih.gov/ dailymed/druglnfo.cfm?setid=6025e8d4-5083-4c3a-58a0-050e7b0b6150. Accessed 26 Feb 2020.

22. Narver HL. Nalbuphine, a non-controlled opioid analgesic, and its potential use in research mice. Lab Anim (NY). 2015:44:106-10. https://doi.org/10. 1038/laban.701.

23. Zeng Z, Lu J, Shu C, Chen Y, Guo T, Wu QP, et al. A comparision of nalbuphine with morphine for analgesic effects and safety : meta-analysis of randomized controlled trials. Sci Rep. 2015;5:10927. https://doi.org/10.1038/ srep10927.

24. Chen MK, Chau SW, Shen YC, Sun YN, Tseng KY, Long CY, et al. Dosedependent attenuation of intravenous nalbuphine on epidural morphineinduced pruritus and analgesia after cesarean delivery. Kaohsiung J Med Sci. 2014;30:248-53. https://doi.org/10.1016/j.kjms.2014.01.001

25. Yeh YC, Lin TF, Chang HC, Chan WS, Wang YP, Lin CJ, et al. Combination of low-dose nalbuphine and morphine in patient-controlled analgesia decreases incidence of opioid-related side effects. J Formos Med Assoc. 2009;108:548-53. https://doi.org/10.1016/S0929-6646(09)60372-7.

26. Zhang S. Clinical observation of low-dose nalbuphine combinedwith sufentanil in PCIA. Acta Acad Med WeiFang. 2016;38:330-2.

27. Niu NYT. nalbuphine combined with sufentanil for clinical observation of analgesia afteradult laparoscopic surgery. World Med Inform Digest. 2017;17:84-6.

28. Gupta M, Gupta P. Nalbuphine pretreatment for prevention of etomidate induced myoclonus: A prospective, randomized and double-blind study. J Anaesthesiol Clin Pharmacol. 2018;34:200-4. https://doi.org/10.4103/joacp. JOACP_210_16.

29. Romagnoli A, Keats AS. Ceiling effect for respiratory depression by nalbuphine. Clin Pharmacol Ther. 1980;27:478-85.

30. Schultz-Machata AM, Becke K, Weiss M. Nalbuphine in pediatric anesthesia. Anaesthesist. 2014;63:135-43. https://doi.org/10.1007/s00101-014-2293-z.

31. Tariq AM, Z. lqbal and Qadirullah. Efficacy of nalbuphine in preventing haemodynamic response to laryngoscopy and intubation. J Postgrad Med Inst. 2014;28:211-6.

32. Chawda PM, Pareek MK, Mehta KD. Effect of nalbuphine on haemodynamic response to orotracheal intubation. J Anaesthesiol Clin Pharmacol. 2010;26: 458-60.

\section{Publisher's Note}

Springer Nature remains neutral with regard to jurisdictional claims in published maps and institutional affiliations.
Ready to submit your research? Choose BMC and benefit from:

- fast, convenient online submission

- thorough peer review by experienced researchers in your field

- rapid publication on acceptance

- support for research data, including large and complex data types

- gold Open Access which fosters wider collaboration and increased citations

- maximum visibility for your research: over $100 \mathrm{M}$ website views per year

At $\mathrm{BMC}$, research is always in progress.

Learn more biomedcentral.com/submissions 